\title{
Rupture of a pseudoaneurysm caused by endoscopic papillary large-balloon dilation
}

Endoscopic papillary large-balloon dilation (EPLBD) is a relatively new technology for removing large bile duct stones [1]. The efficacy and safety of EPLBD have been reported; however, severe complications occur in approximately $10 \%$ of patients [2]. Hemorrhage is one of the most common complications, and endoscopic hemostasis is effective [3]. Herein, we present a case of rupture of a pseudoaneurysm following EPLBD.

A 71-year-old woman with recurrent bile duct stones was admitted to our institution. She had a previous history of recurrent episodes of acute pancreatitis. A large stone, $28 \times 10 \mathrm{~mm}$ in size, was seen on computed tomography ( $\bullet$ Fig.1). Contrast-enhanced computed tomography was not performed because of the pa-

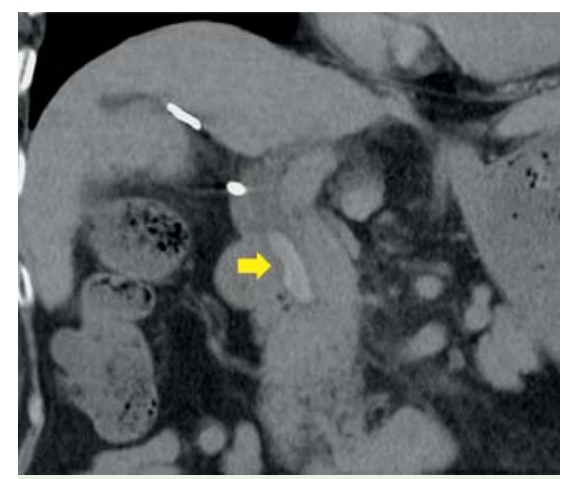

Fig. 1 Coronal computed tomographic scan shows a large $(28 \times 10-\mathrm{mm})$ stone (arrow) in the common bile duct of a 71-year-old woman with recurrent bile duct stones and a previous history of acute pancreatitis. tient's renal dysfunction. Endoscopic retrograde cholangiography revealed an oblong-shaped filling defect in the common bile duct ( $\bullet$ Fig. 2 a). EPLBD with a balloon catheter (CRE Wireguided Balloon Dilator, 15 - 18 mm; Boston Scientific, Natick, Massachusetts, USA) was performed to remove the bile duct stone ( Fig. $\mathbf{2}$ b). Spurting bleeding was observed immediately after the balloon had been deflated ( $\bullet$ Fig.3a). Neither balloon oppression nor placement of a fully covered self-expandable metallic stent with a diameter of $10 \mathrm{~mm}$ was effective for hemostasis ( Fig.3b). Emergency abdominal angiography was performed, and angiography of the gastroduodenal artery revealed a pseudoaneurysm of the gastroduodenal artery with extravasation into the duode- num ( $\bullet$ Fig.4a, $\bullet$ Fig.4b). The placement of five coils achieved complete hemostasis ( $\bullet$ Fig.5). The patient was discharged on postoperative day 9 without further complications.

To our knowledge, this is the first report of pseudoaneurysm rupture as a complication of EPLBD. Because this patient had a history of recurrent episodes of acute pancreatitis, a pseudoaneurysm was possible. However, we had no chance to notice the pseudoaneurysm because contrast-enhanced computed tomography was contraindicated owing to her renal dysfunction.

Care should be taken to evaluate patients undergoing EPLBD with contrast-enhanced computed tomography to detect any arterial abnormality.

\section{Endoscopy_UCTN_Code_CPL_1AK_2A}

\section{Competing interests: None}
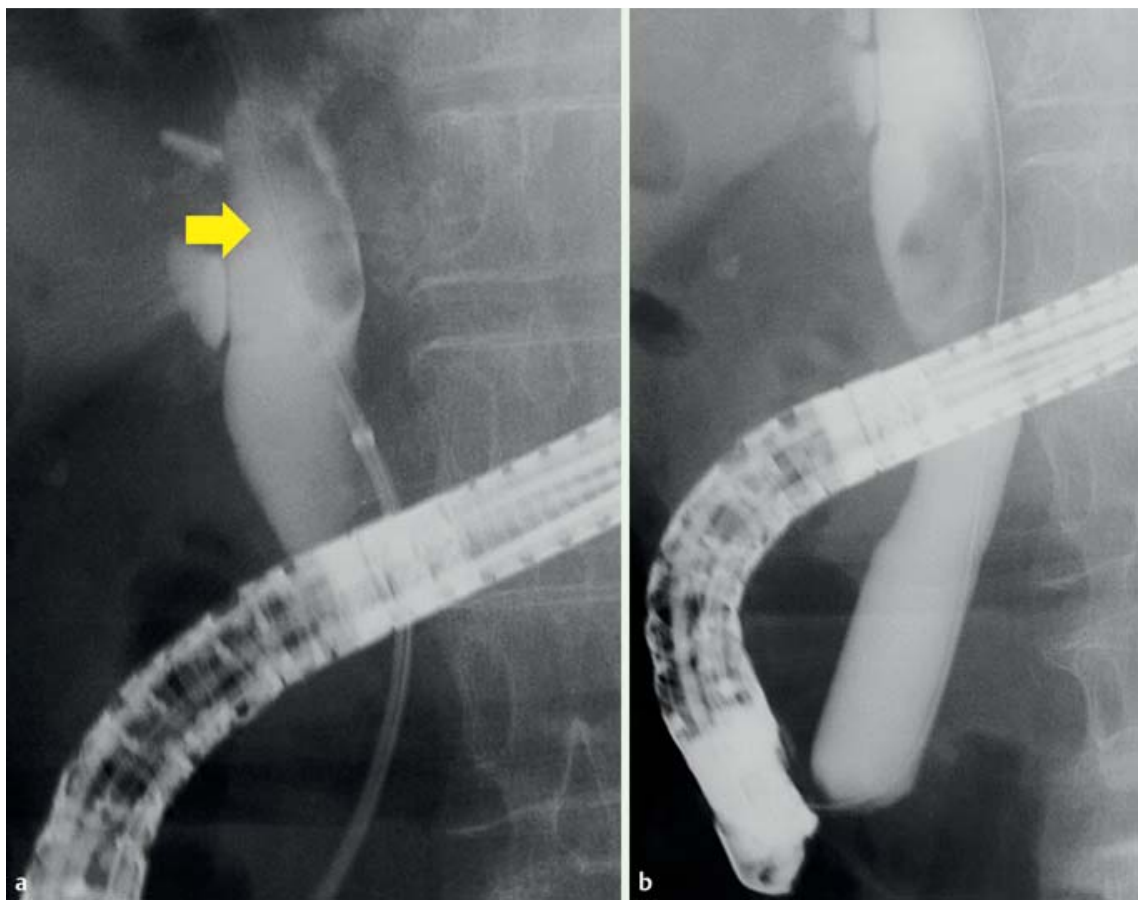

Fig.2 Images obtained during endoscopic retrograde cholangiography. a An oblong-shaped defect is observed in the bile duct (arrow). $\mathbf{b}$ Endoscopic papillary large-balloon dilation is performed with a balloon that has a diameter of $18 \mathrm{~mm}$. 


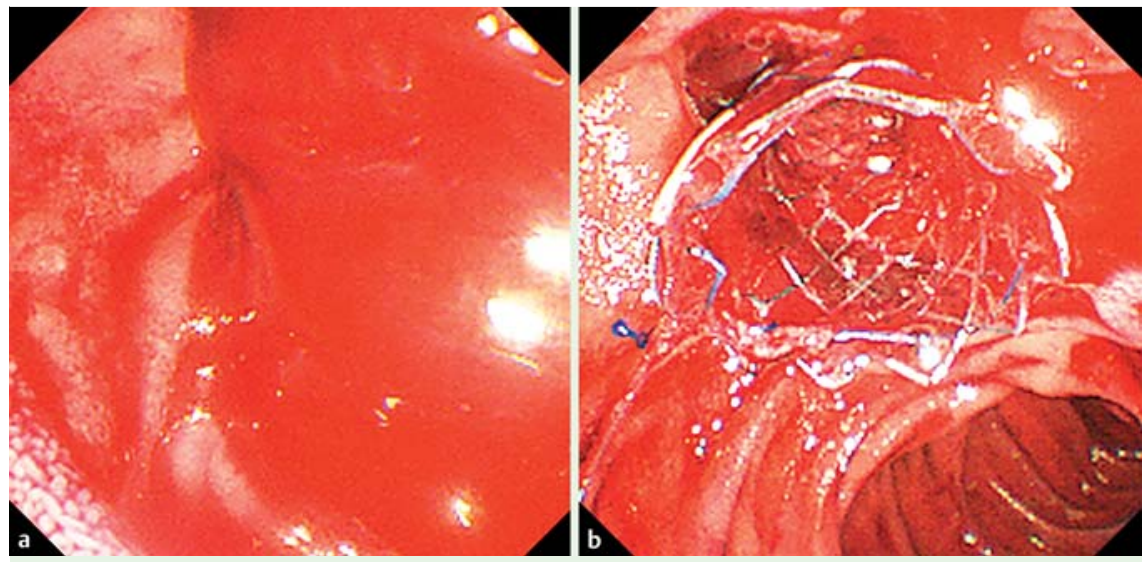

Fig. 3 Endoscopic images of the ampulla of Vater. a Spurting bleeding is observed after endoscopic papillary large-balloon dilation. $\mathbf{b}$ Continuous bleeding is observed after the insertion of a metallic stent.

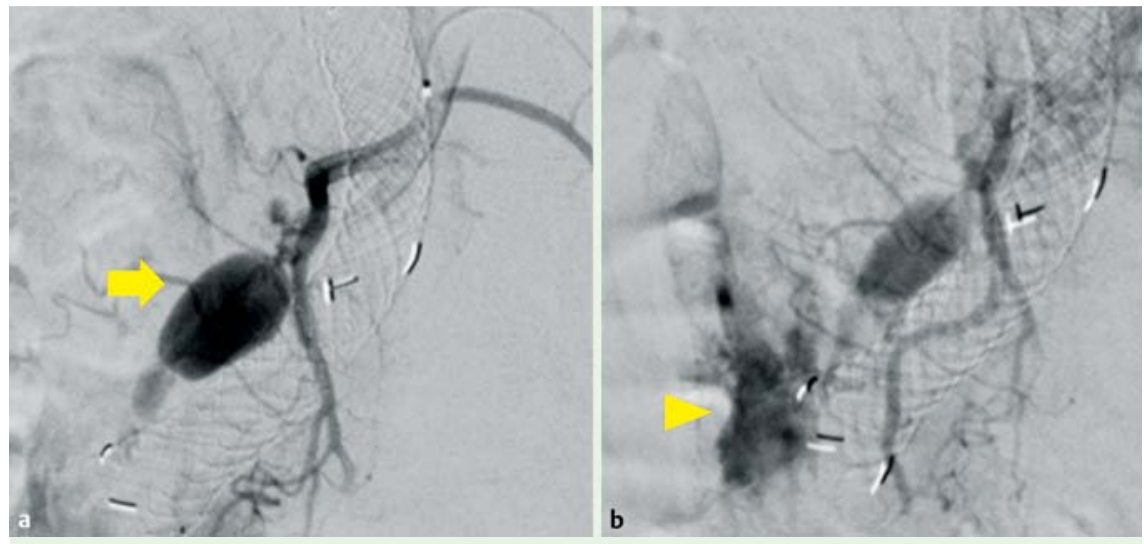

Fig. 4 Angiographic images. a A pseudoaneurysm is observed (arrow). b Extravasation into the duodenum (arrowhead).

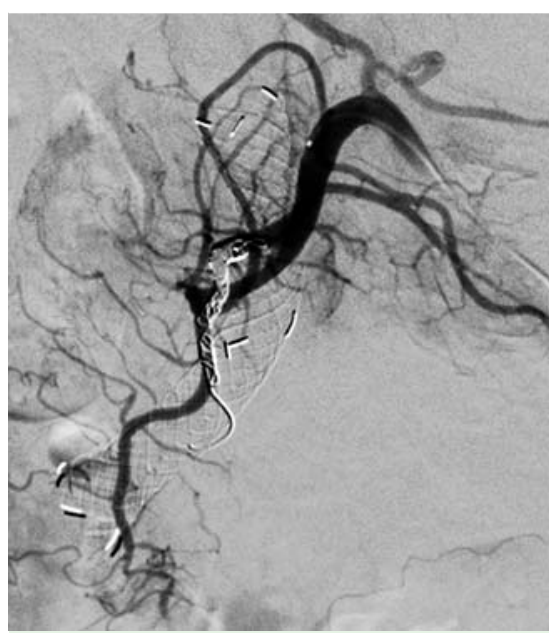

Fig. 5 Hemostasis after the placement of five coils is confirmed by celiac angiography.
Akira Kurita, Takashi Ito, Yasushi Kudo, Shujiro Yazumi

Division of Gastroenterology and Hepatology, Digestive Disease Center, Kitano Hospital, The Tazuke Kofukai Medical Research Institute, Osaka, Japan

\section{References}

1 Ersoz G, Tekesin O, Ozutemiz AO et al. Biliary sphincterotomy plus dilation with a large balloon for bile duct stones that are difficult to extract. Gastrointest Endosc 2003; 57: $156-159$

2 Park SJ, Kim JH, Hwang JC et al. Factors predictive of adverse events following endoscopic papillary large balloon dilation: results from a multicenter series. Dig Dis Sci 2013; 58: 1100-1109

3 Shimizu S, Naitoh I, Nakazawa T et al. Case of arterial hemorrhage after endoscopic papillary large balloon dilation for choledocholithiases using a covered self-expandable metallic stent. World J Gastroenterol 2015; 21 : 5090-5095

\section{Bibliography}

DOI http://dx.doi.org/

10.1055/s-0034-1393039

Endoscopy 2015; 47: E532-E533

(c) Georg Thieme Verlag KG

Stuttgart · New York

ISSN 0013-726X

\section{Corresponding author}

\section{Akira Kurita, MD}

Division of Gastroenterology and Hepatology Digestive Disease Center

Kitano Hospital

The Tazuke Kofukai Medical Research Institute 2-4-20 Ohgimachi

Kita-ku

Osaka 530-8480

Japan

Fax: +81-6-6312-8867

kuritaaki1976@gmail.com 